\title{
The Cracking of Lead Cable Sheathing.
}

A PAPER on the important practical subject of A "The Deterioration of Lead Cable Sheathing," by Messrs. S. Beckinsale and $H$. Waterhouse, read at the spring meeting of the Institute of Metals, represents work done in the Research Department, Woolwich, for the British Non-Ferrous Metals Research Association. The authors have examined a large number of lead cable sheaths which have failed in service by inter-crystalline cracking, and it was found in all cases that the material which had failed was lead of a high degree of chemical purity. It has been suggested that this type of cracking may have resulted from overheating during the extrusion of the sheath. It is shown, however, in the present paper that for lead of the composition generally used, working can be done from room temperature up to within a few degrees of the melting point without leading to cracking, and the only difference observed in the lead rolled at different temperatures was that the grain size tended to increase as the temperature was raised. It was not found possible to reproduce any cracking corresponding with that observed in service by variations of the working temperature.

It has been observed previously that the structure of the same cable sheath varies very appreciably so far as the size of the crystals is concerned. This point has been taken up with considerable care by the present authors, and they have shown that there is no probability that appreciable grain growth has occurred during service. They have also failed to find any reason to believe that there is a relationship between the frequency of the cracking and the crystal size. This type of cracking has also been attributed to allotropic changes in the lead, but careful work, both pyrometric and mechanical, has failed to reveal any evidence of such allotropic change, and it is considered that the possibility of such things being in any way responsible for the cracking must be dismissed.

Cracking is well known to occur in brass which is subjected to the simultaneous effect of stress and corrosive action. Similar cracking in lead has been obtained under the combined action of tensile stress and corrosion with solutions of acetic acid or lead acetate. It is not believed, however, that such corrosive attack can have any important bearing on the present subject, since it was observed that the cracking in service commenced on the inner surface of the sheath and spread outwards, and that it was not until the cracks had reached the exterior surface that the slightest evidence of local corrosion of the inner surface could be detected. It was shown, however, that while silver, copper, bismuth, and nickel all diminished the resistance of lead to corrosion in soluble acetates, arsenic, cadmium, and particularly tin and antimony, all rendered lead more resistant. There are cases on record where acetic or some other organic acid appears to have played an important part in the failure by corrosion of lead sheet and cable sheathing which had been in contact with oak, though pitch pine and deal appear to be without action. Creosote, if free from acetic acid, also has no influence in the production of intercrystalline cracking.

The failure of the sheathing occurs generally in situations subject to vibration, or where the metal is subject to changes of length due to fluctuations of temperature, and the view that the cracking is due to "fatigue' is one for which there is considerable support. Fatigue tests have been carried out which indicate a range of stress at the fatigue limit of ap. proximately only 0.18 ton per square inch, and cracks were found in the fatigue test pieces which bear a striking relationship to those in the cable sheathing which had failed.

Since the cracking in service was thus in all probability due to fatigue, experiments were carried out with lead alloys in which the fatigue limit was higher. Even very small amounts of metals, such as bismuth and silver, which are regarded as undesirable impurities in certain respects, have a beneficial effect in raising the fatigue limit. The most satisfactory method of doing this, however, is to use the binary or ternary alloys of lead containing tin, antimony, or cadmium; 0.5 per cent of cadmium increases the fatigue limit to more than three times that of pure lead, while similar increases can be obtained by using ternary alloys containing cadmium and either tin or antimony. These ternary alloys have not only a high fatigue limit, but they also have a permanence of composition during melting and a resistance to oxidation at raised temperatures which are superior to those of the binary alloys, while in addition they possess good corrosion-resisting properties. F. C. T.

\section{University Statistics, ${ }^{1}$ I926-27.}

GINCE the acceptance by Oxford and Cambridge of annual parliamentary grants and the consequent inclusion of these two universities in the University Grants Committee's returns, these statistics have presented a fairly comprehensive survey of university work in Great Britain. For five years now the returns have comprised all universities and, with few exceptions, all university colleges in Great Britain, and it seems a pity that they are not supplemented by others, in identical form, for the excepted institutions.

The total number of full-time students of both sexes in $1926-27$ was 42,354 . The proportion of women to men has risen during the past five years from $14: 36$ to $15: 35$. In England as a whole women formed, in 1926-27, 28.3 per cent of the total number; in Wales, $39 \cdot 3$ per cent; in Scotland, 34 per cent;

1 Returns from Universities and University Colleges in receipt of Treasury Grant. 1926-27. (London: H.M. Stationery Office, 1928.) Pp. 24. 3s, net.

No. 3058 , VoL. 121] in London institutions, $35 \cdot 7$ per cent. Since the War the large body of students aided under the government scheme for the higher education of ex-service men has obscured the situation in regard to student enrolments. As this large body has gradually passed. out of the universities the total number of men students has continuously fallen until 1925-26, when only 17 of the ex-service scholarship holders remained. Now for the first time the actual tendencies of student enrolments to increase are exhibited in the returns, which show an increase of 748 (men 658, women 90) over the number of full-time students in the preceding year. If from the figures shown in the returns for preceding years the number of ex-service scholarship holders are deducted, the decreases shown in 1925-26 and 1924-25 are converted into increases of 58 and 360 respectively, and the decrease in 1923-24 is reduced to 113. Similarly, the increase in the proportion of women is converted to a slight decrease. 
Since 1922-23 a very remarkable change has taken place in what may be called the balance of university studies-the distribution of full-time students among the main subject groups. Between 1913-14 and 19221923 the returns (in which, as already stated, Oxford and Cambridge were not included) showed a fall of more than five per cent in the percentage of the total represented by students in the arts group (including theology, fine art, law, music, commerce, economics, and education), whilst the percentage represented by the medical group rose by more than three, and the percentage of the other three groups, pure science, technology, and agriculture, rose very slightly. Since 1922-23, on the other hand, the returns, including now Oxford and Cambridge, show a rise in the percentage of the arts group from $40 \cdot 8$ to $5 \mathrm{I} \cdot 7$, whilst the number of students in that group has risen by above 3500 , despite a fall of more than 2000 in the grand total of students. The position of the pure science and agriculture groups has remained fairly steady, but for the medical and technology groups both percentages and actual numbers have markedly decreased, namely, from 11,866 (26.6 per cent) and $5567(12.5)$ to $8415(19.9)$ and $3970(9 \cdot 4)$ respectively. The greatest changes were in Scotland, where the percentage of the medical group fell from $35 \cdot 2$ to $22 \cdot 7$, while the percentage of the arts group rose from $38 \cdot 9$ to $56 \cdot 1$.

This extraordinary rise in favour of the arts group of subjects is attributed by the University Grants Committee to the attraction exercised, during a period of bad trade and restricted opportunities in other professions, by the improved prospects offered by the profession of teaching. This explanation is supported to some extent by statistics of teachers in grant-aided secondary schools in England and Wales. Between 1922 and 1927 their total number increased by 676 , while the number of those of them who were university graduates increased by more than two thousand,-from 11,937 to 14,019 - the increases year by year being $241,419,552$, and 870 . Clearly the teaching profession has been absorbing a largely increasing proportion of the universities' output of graduates. The falling off in the number of the technological students is, the Committee considers, due to the continuance of serious depression in many industries.

A similar rise in favour of the arts group of subjects and decline in number of students of technology are disclosed by recent statistics of university education in Prussia. The years 1924 to 1927 have seen in Prussia a steady decline in the student enrolments of the Technischen Hochschulen from 8603 to 7936, whilst most of the subjects grouped under the heading of arts show an increase, which is most noticeable under modern languages. Of interest in this connexion are the following extracts from the United States Bureau of Education's biennial survey of higher education, 1924-26: "Immediately after the War ... the idea gained ground that educational institutions should emphasize training to very specific objectives. The two-year period under review gives many indications that there has been a decided reaction ... a returning faith, if not in the disciplinary value of the so-called cultural subjects, at any rate in their practical value and in the habits of application developed by the exertion required to master them."

A new table, introduced for the first time last year, classifies research and other advanced students under the branches of study in which they were engaged. Under certain branches of science it gives the following numbers of full-time advanced students : chemistry 511 , engineering 141 , physics 132 , botany 83 , geology 52, mathematics 47 , zoology 43 , metallurgy 42 , agriculture 35, physiology 33. Commenting on the dominant position of chemistry, the Committee suggests that the other sciences, and especially the biological sciences other than medicine, have been far too much neglected by advanced students at the universities. It observes also in regard to chemistry that the immediate demand is more for men who have combined a study of this subject with such other subjects as engineering, agriculture, bio-chemistry, and botany than for men whose special knowledge is confined to the ordinary branches of pure chemistry.

\section{Annual Visitation of the Royal Observatory, Greenwich.}

$\mathrm{T}$ HE visitation of the Royal Observatory, Greenwich, took place on Saturday, June 2, and was attended, as usual, by a large gathering of astronomers and their friends. The Astronomer Royal presented his report for the year ended on May 10 last.

The usual observations of sun, moon, planets, and stars were made with the transit circle. The moon's longitude was $6 \cdot 2$ " in advance of that given by Brown's tables. The residual has been diminishing by $0 \cdot 2^{\prime \prime}$ per annum since the new tables were introduced in 1923. The latitude is systematically south of the tables by 3". It will be remembered that Brown removed the constant term of $1^{\prime \prime}$ which Hansen had applied to the latitude, but the observations show that some such term is needed. The catalogue of 11,000 stars between declination $32^{\circ}$ and $64^{\circ}$ is making good progress, and should be finished in 1930. The stars selected as comparison stars for Eros in 1931 are also being observed; they are so closely packed that it is difficult to get sufficient observations of each of them.

A re-discussion of the declinations of stars near the pole shows that there is no evidence of secular change of latitude since the erection of the transit circle in 1851. The observations would scarcely permit of a greater change than $0 \cdot 1^{\prime \prime}$ per century. The observa- tions with the Cookson floating zenith telescope have been discussed both for latitude variation and aberration. The aberration constant for the seven years $1919-26$ is $20.447^{\prime \prime}$; that for the previous seven years was $20.442^{\prime \prime}$; the corresponding values of the solar parallax are $8 \cdot 814^{\prime \prime}$ and $8 \cdot 816^{\prime \prime}$. The parallaxes of 39 stars were determined from photographs with the Thompson equatorial, bringing the total up to date to 369 stars.

Spectroscopic observations of the "colour-temperature' of early-type stars have been continued with the 30 -inch reflector; the spectroscope has been modified by the substitution of a mirror for the lens; this enables the investigation to be carried farther towards the red end of the spectrum, which previously was in bad focus. The micro-photometer has also been modified to permit shorter sections of the spectrum to be measured, thus avoiding regions of absorption. The 30-inch reflector was also used for the photography of comets Grigg-Skjellerup and Pons-Winnecke The latter was photographed when very near the earth, its angular motion being nearly equal to that of the moon. Its nucleus at that time was quite small and stellar, permitting accurate measures to be made.

The astrographic equatorial is being used for

No. 3058 , VoL. 121] 